\title{
UM MODELO DE JOGO PARA O VOLEIBOL NA AREIA
}

Nelson Kautzner Marques Júnior

\section{Resumo}

O objetivo da revisão foi de sugerir um modelo de jogo para o voleibol na areia. Para esse modelo de jogo ser eficaz o atleta precisa realizar prioritariamente o saque em suspensão, fazer o levantamento com variação para o ataque e durante o bloqueio o atleta deve tentar o ponto. Um bom bloqueio facilita a defesa. Talvez a variação ofensiva através do levantamento em certos momentos após a defesa o voleibolista pode se cansar menos porque ele recebe um levantamento num local que ele não se desgasta muito e efetuando o ataque com tranqüilidade. Entretanto, esse modelo de jogo não é o comum do voleibol na areia da atualidade. Conclui-se que para esse modelo de jogo ser determinado como eficaz merece acompanhamento de cientistas e técnicos.

\section{Palavras-Chave}

Voleibol; Modelo de jogo; Tática; Performance.

\section{A MODEL OF PLAY FOR THE BEACH VOLLEYBALL}

Nelson Kautzner Marques Júnior

\begin{abstract}
The objective of the review was to suggest a model of play for the beach volleyball. The model of play was good with jump service, varied setter for the attack and during the block the objective of the athlete is the point. A good block helps the defense of the volleyball player. Perhaps, varied setter causes little fatigue because the athlete after the defense has a ball for the attack next with objective of no run more. However, this model of play no is traditional of the beach volleyball. In conclusion, theory and practice are important for determines the quality this model of play.
\end{abstract}

\section{Key-Words}

Volleyball; Model of play; Tactics; Performance. 


\section{INTRODUÇÃO}

O voleibol de dupla na areia de alto rendimento é um esporte muito exigente no aspecto físico, técnico-tático e psicológico (STEFANELLO, 2007). Uma partida de voleibol na areia costuma ter duração de 1 hora (BAHR; REESER, 2003; GIATSIS, 2003), não possuindo substituição de atleta, jogada na areia fofa que dificulta as ações do voleibolista (HESPANHOL, et al., 2006) e costuma ser competido sob forte calor (MARQUES JÚNIOR, 2002) que desencadeia diversas reações fisiológicas para o esportista agüentar o estresse do meio ambiente (MARQUES JÚNIOR, 2008). Contudo, apesar dos riscos para a saúde do atleta, o voleibol na areia continua sendo disputado sob essas condições ou até chuviscando. Então, o competidor do voleibol necessita de constante aperfeiçoamento para ser melhor do que o oponente e ter condição superar as variáveis intervenientes da partida (torcida, clima, piso, vento, sol, chuva) (MENEZES; MENEZES; SANTOS, 2008; NOCE; SAMULSKI, 2002; VIEIRA. et al., 2008). Mesmo com todas essas dificuldades que o voleibol de dupla na areia apresenta, ele é jogado em alta velocidade na fase ativa (BENETTI; SCHNEIDER; MEYER, 2005; MARQUES JÚNIOR, 2006), acontecendo a proporção de 5 por 3 durante um rali, ou seja, cinco ações de intensidade máxima (saltos e defesas com deslocamento) para três atividades submáxima e moderada (levantamento sem salto, saque tipo tênis ou outro e recepção) (ARRUDA; HESPANHOL, 2008b). Apesar dessa alta velocidade das ações no jogo de dupla, a partida possui maior período de pausa (ativa ou passiva), possibilitando a recuperação do voleibolista após o esforço da jogada (RESENDE; SOARES, 2003). Portanto, esse esporte é uma modalidade intermitente (BISSOCHI, 2005). Onde a tática assume capital importância durante a partida ( $\mathrm{O}$ que fazer), sendo executado o pensamento tático pelos fundamentos (Como fazer) (COLLET et al., 2007). A memória declarativa e a memória de procedimento atuam em conjunto na partida, mas a primeira é mais atuante na tática e a segunda no fundamento, elas trabalham juntas para resolver a situação problema da jogada.

O desempenho esportivo de um atleta de voleibol consiste da união durante a partida pelos componentes técnicos, táticos, físicos e psicológicos (ARRUDA; HESPANHOL, 2008b). A integração desses componentes só faz efeito se a dupla de voleibol estiver utilizando o sistema 1x1 (um ataca e outro levanta) com um adequado modelo de jogo. Entretanto, no voleibol na areia da atualidade o modelo de jogo é muito previsível, ou seja, no início do jogo ocorre o saque, na construção do ataque o atleta faz o passe e o levantamento e na finalização ofensiva é efetuada a cortada ou a largada em uma das pontas (entrada ou saída da rede). A dupla que não está com a bola e que fez o saque, pouco depois do ataque faz o bloqueio (ofensivo ou defensivo) e um jogador se posiciona para realizar a defesa. Essas ações acontecem durante toda a partida, a diferença das melhores duplas para as inferiores é o pouco erro em todos os fundamentos, tendo um saque forte de alta 
regularidade, possuindo um ataque forte com precisão e o bloqueio costuma pontuar (LACERDA; MESQUITA, 2003; MESQUITA; TEIXEIRA, 2004). Logo, o único meio para diminuir essa previsibilidade do modelo de jogo é estruturar um modelo de jogo que acarrete imprevisibilidade da "leitura" de jogo pelo adversário. Para tal tarefa acontecer, necessita de estudo sobre a tática para aplicar no modelo de jogo (COSTA; NASCIMENTO, 2004; GARGANTA, 2006; MORALES; GRECO, 2007), merecendo depois que essa teoria seja posta em prática para ser corroborada as informações dessa revisão de literatura. A figura um expõe como estruturar um modelo de jogo para o voleibol na areia com evidências científicas.

\section{TEORIA}

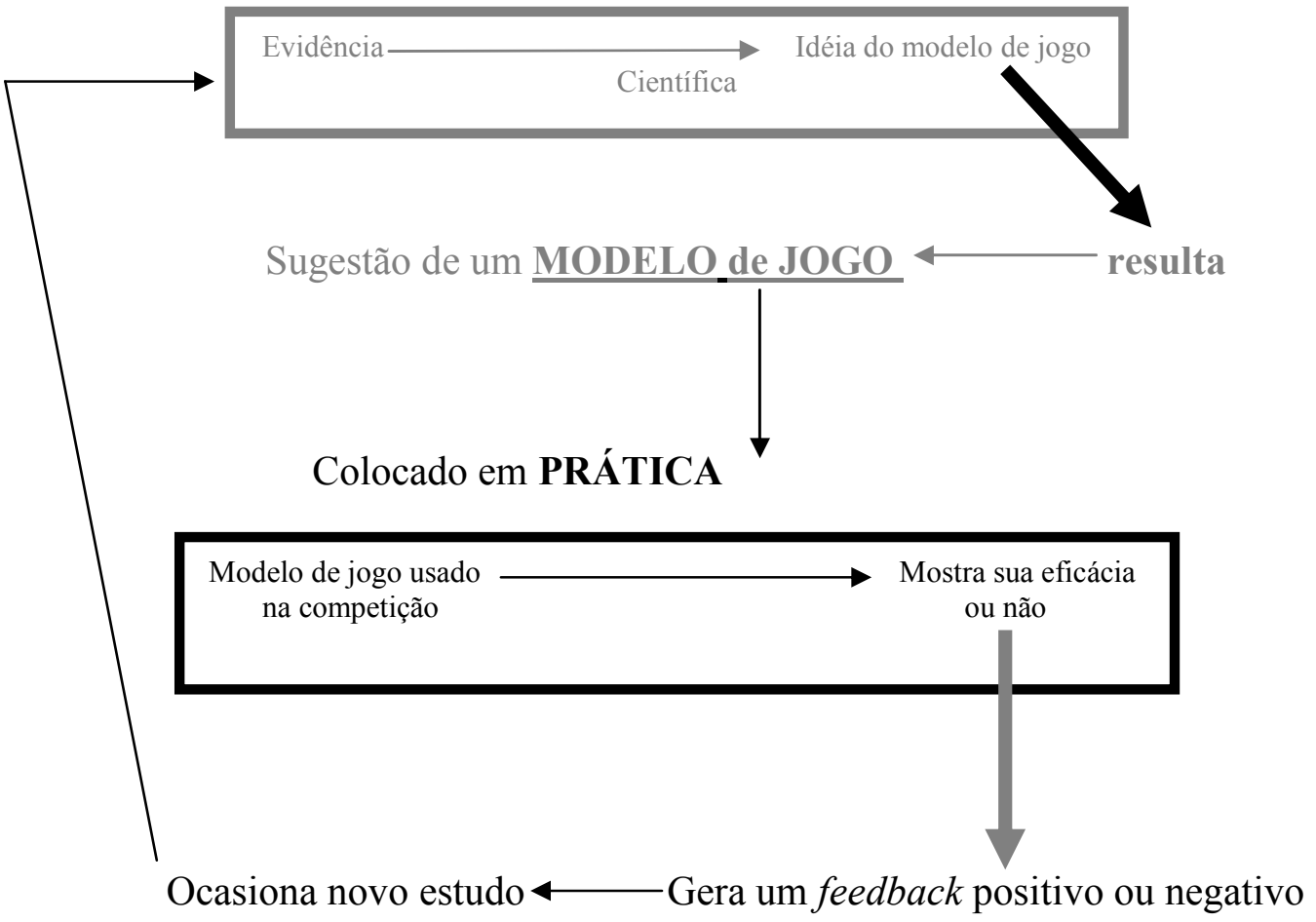

Figura 1- Ciclo da teoria-prática na elaboração de um modelo de jogo.

O objetivo da revisão foi de sugerir um modelo de jogo para o voleibol na areia.

\section{MODELO DE JOGO}

O sistema de jogo do voleibol de dupla na areia é o 1 (ataca) x 1 (levanta). Tendo como modelo de jogo uma maneira de atuar na partida com previsibilidade onde vai ser levantada a bola para ocorrer o ataque. Do lado do oponente é combinado se o bloqueio vai acontecer na direção da paralela ou da diagonal para orientar o 
defensor em permanecer onde esse fundamento não vai cobrir a quadra. Apesar dos melhores do mundo jogarem com esse modelo de jogo a ciência pode mostrar uma nova maneira dos atletas atuarem na partida do voleibol na areia. Uma dupla de voleibol consegue prejudicar o ataque do oponente com um bom saque, geralmente efetuado pelo saque em suspensão (UREÑA et al., 2000). O saque eficaz proporciona em ponto ou interfere na recepção que dificulta o levantamento (JOÂO et al., 2006) e pode ocasionar caso o atleta não consiga acertar esse fundamento, numa armação de ataque deficiente para o cortador (CAVALHEIRO; TAVARES, 2003). Um levantamento ruim necessita de extrema habilidade do atacante para realizar um bom remate. Sucessivos saques em suspensão de qualidade podem facilitar a defesa porque existe uma tendência da cortada ser deficiente em certos momentos (PALAO; SANTOS; UREÑA, 2004). Também o bom saque em suspensão costuma ocasionar em bloqueios eficazes que geram ponto ou tornam possível a defesa. Porém, Bizzocchi (2004) orientou que variar o tipo de saque se torna um meio eficaz para dificultar a ação do passador, merecendo o uso do saque tipo tênis. Para esse saque ter mais chance de ponto deve ser aplicado com a bola parada, sem giro porque a crise do arrasto ocasiona mudança na trajetória da bola (DEPRÁ; BRENZIKOFER, 2004). Isto acontece por causa da interação da bola com o ar, gerando turbulência na bola e proporcionando uma queda repentina da bola no solo. Então, a ênfase do saque deve ser o "viagem ao fundo do mar" porque possibilita mais chance de ponto (UGRINOWITSCH; UEHARA, 2006), mas de vez enquanto o esportista merece efetuar o saque tipo tênis para um descanso ativo após uma jogada intensa, com o intuito de evitar o erro consecutivo desse fundamento ou visando fazer um ponto porque a característica desse saque difere do saque em suspensão.

A recepção do voleibol na areia costuma direcionar para o parceiro que futuramente fará o levantamento. Recomenda-se quando o saque permitir, que o recebedor do saque faça um passe preparando a bola para a cortada do seu colega de dupla. Esta iniciativa dificulta a ação do bloqueio porque o cortador pode desferir um ataque que não dá tempo de bloqueio ou fingir que vai cortar e levantar a bola para o atleta que fez o passe, ou seja, fintar o bloqueio e deixar o atleta de equipe em condições de facilidade para realizar o remate. Em relação ao levantamento, costuma-se praticar pela bola alta em uma das pontas da rede. Sempre ocorre a mesma jogada de armação de ataque. Consultando a literatura sobre a distribuição, ela informou que o ataque acontece com mais facilidade se ocorrer uma variedade de levantamentos nas diversas regiões da quadra (RAMOS et al., 2004) e dando preferência à distribuição de bola rápida que dificulta o bloqueador e a defesa chegar no remate (CUNHA; MARQUES, 2003). Geralmente no voleibol na quadra os vencedores são as equipes com levantamentos mais variado (CEZARANO; ROCHA, 2006), o mesmo deveria ser realizado no voleibol na areia. Mas para tal acontecer com qualidade é necessário que o levantador tenha elevado 
conhecimento tático (MESQUITA; GRAÇA, 2002). Por exemplo, num determinado momento à distribuição de bola rápida é no meio da rede, depois é na saída da rede em seguida é realizada na linha imaginária dos $3 \mathrm{~m}$ e outros. A variação na preparação do ataque com bola rápida aumenta a imprevisibilidade sobre o futuro remate, gerando segundo César e Mesquita (2006) mais complexidade na maneira de jogar. Resultando em mais chance de sucesso na atividade ofensiva (ROCHA; BARBANTI, 2004) porque no voleibol na quadra da atualidade a variabilidade ofensiva permite diferir os melhores para os inferiores (GOUVÊA; LOPES, 2008), sendo interessante o uso dessas informações voleibol na areia. As duplas vencedoras numa quadra de 8x8 costumam possuir mais eficácia ofensiva (GIATSIS; TZETZIS, 2003). Para a dupla marcar onde vai acontecer à distribuição de bola rápida pode ser efetuado antes ou pouco antes do levantamento pela comunicação verbal ou por sinais, também pode ser realizado conforme o local para onde o atacante corre na quadra que será feita a preparação do remate. Após o levantamento o atleta que praticou essa técnica esportiva precisa fazer a cobertura de bloqueio com o intuito de dificultar o retorno da bola no solo caso o remate toque no bloqueio do adversário e volte para sua quadra. As Figuras 1 e 2 ilustram esta explicação:

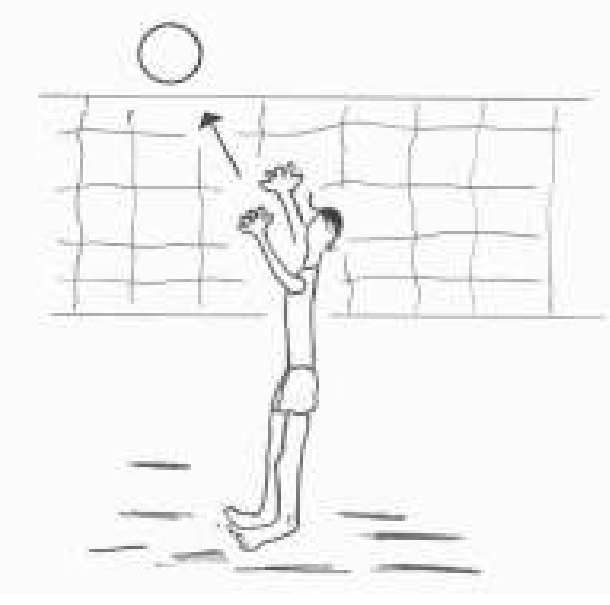

Figura 1- Levantamento. 


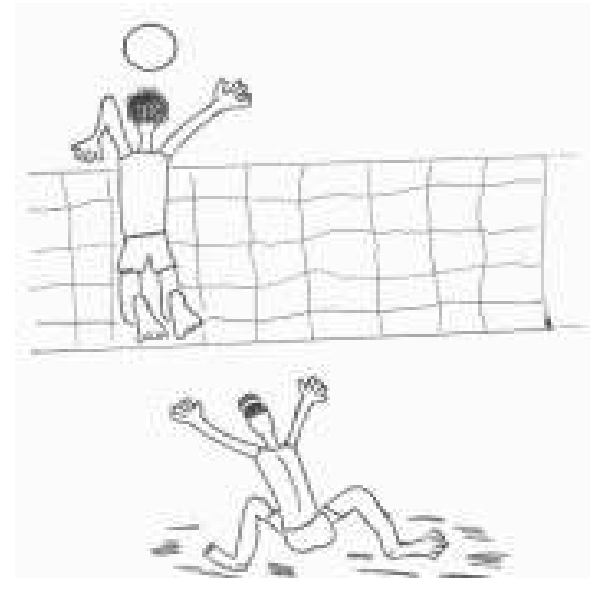

Figura 2 - Cobertura de bloqueio após o levantamento.

Esta armação de ataque com variação da distribuição e tendo preferência na bola rápida permite destacar algumas questões que são as seguintes:

a) O levantamento com variação causa um menor dispêndio energético no cortador em algumas jogadas?

b) A preparação variada de ataque com bola rápida dificulta o bloqueador em adquirir o tempo de bola do cortador?

Marques Júnior e Kimura da Silva (2006) informaram que os maiores esforços do voleibol são os saltos (estando presente no saque, cortada, bloqueio e levantamento) e os deslocamentos defensivos com defesa. Em alguns momentos do jogo de dupla, o atacante corta colocado no fundo da quadra, imediatamente o atleta corre e depois faz a defesa, geralmente com um mergulho (popular "peixinho") se for na quina da paralela. Utilizando o modelo de jogo sugerido neste artigo, após a defesa o atleta da distribuição faz o levantamento para ser efetuado o remate dos $3 \mathrm{~m}$ com o intuito de não cansar em demasia o jogador e causar variação ofensiva. Contudo, somente através de pesquisa pode-se determinar que esta tarefa causa menor dispêndio energético. A Figura B demonstra o ensinado: 


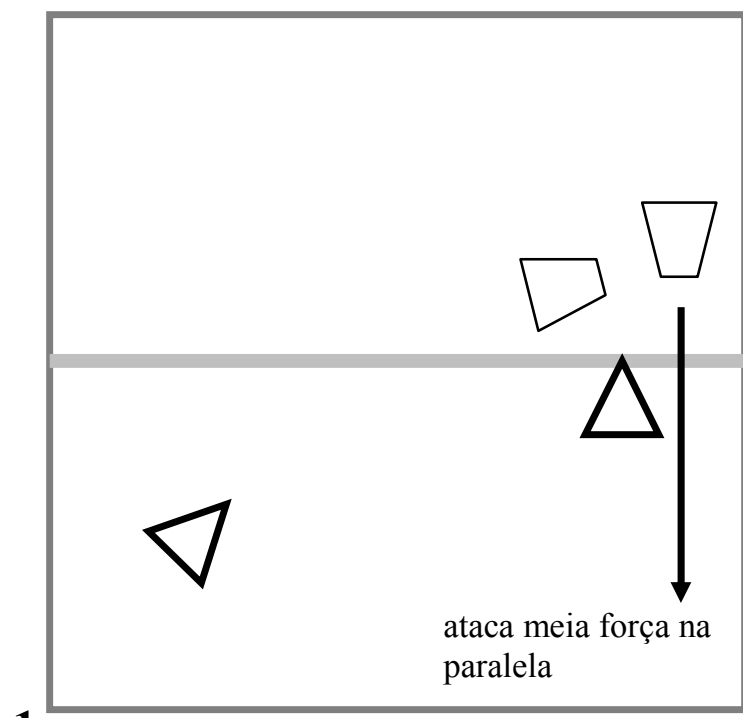

1

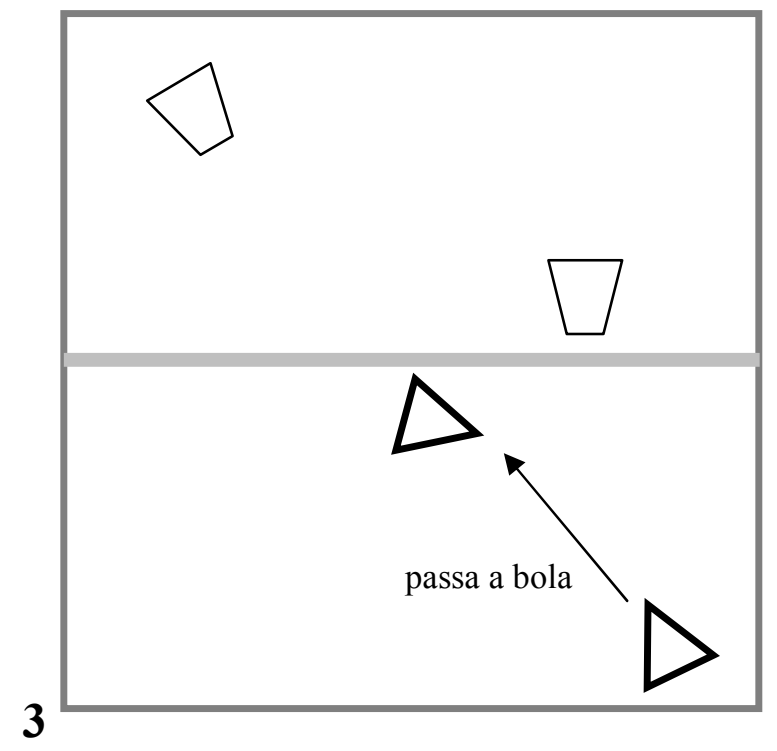

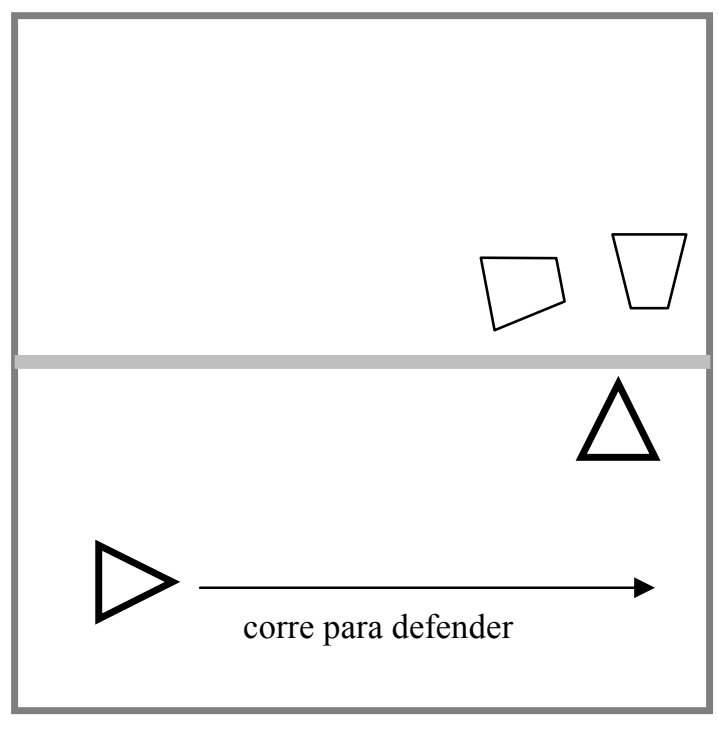

2

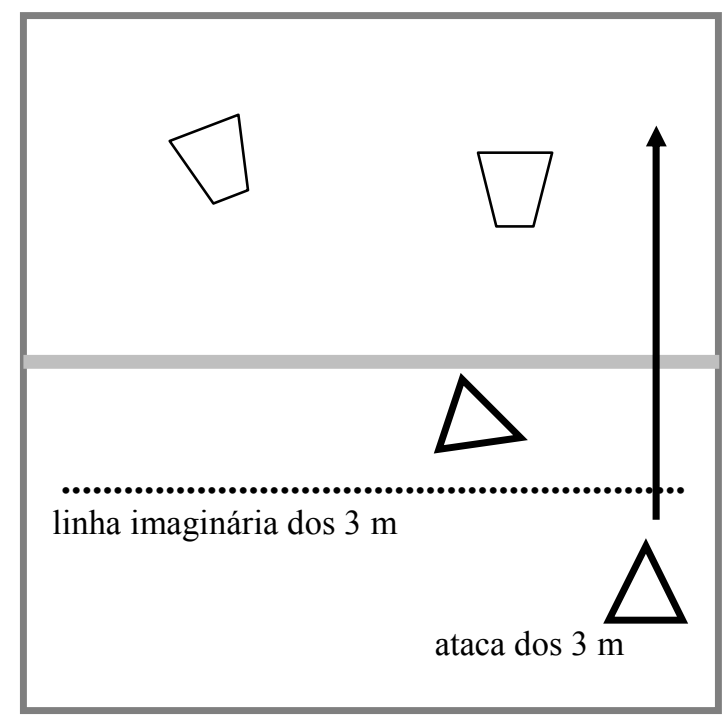

Figura 3 - Jogada com possível menor esforço.

Rizola Neto (2003) afirmou que o bloqueador precisa adaptar-se rápido ao tempo de bola do cortador e analisar as características desse atacante, ou seja, locais onde mais ataca, velocidade do braço de golpe na bola e outras ações. O modelo de jogo atual onde ocorre ataque de bola alta na ponta facilita o bloqueador em realizar esta tarefa porque a atividade ofensiva é sempre a mesma. Mas com distribuição variada em diversos locais da quadra e tendo prioridade as bolas de velocidade o trabalho do bloqueio não vai ser tão fácil 
(RAMOS et al., 2004). Então, a preparação do ataque com esse tipo de levantamento talvez cause uma supremacia da cortada em relação ao bloqueio. Caso uma equipe atue com esse modelo de jogo na distribuição variada de bola rápida, indica-se como local inicial da atividade de bloqueio a partir do meio da rede porque fica mais rápido chegar em uma das pontas com o deslocamento frontal e tendo o balanceio dos braços antes de realizar este fundamento para resultar em maior elevação do centro de gravidade. Esta tarefa é igual ao do voleibol na quadra. Caso o ataque acontece na região central da rede, o jogador se encontra no local do remate, podendo fazer o bloqueio ou dar algumas passadas laterais e imediatamente praticar essa técnica esportiva. Para o bloqueador conseguir sucesso com a variabilidade ofensiva necessita de apurada percepção (GASPAR; FERREIRA; PÉREZ, 2005), atenção e de uma boa análise visual (FORD; HODGES; WILLIAMS, 2007; SOUZA; OLIVEIRA; OLIVEIRA, 2006) a fim de realizar essa técnica com qualidade porque o bloqueio é fundamental no voleibol da atualidade (OLIVEIRA; MESQUITA; OLIVEIRA, 2005).

O bloqueio e a defesa são outras questões que precisam de atualização do voleibol na areia atual. O bloqueador combina com o defensor onde vai acontecer o bloqueio, na paralela ou na diagonal, enquanto que o homem da defesa costuma se posicionar onde não tem bloqueio. Quando uma cortada é desferida atinge uma velocidade próxima ou superior a $100 \mathrm{~km} / \mathrm{h}$. Russo (2002) informou que as chances de defesa são mínimas porque o voleibolista gasta alguns centésimos no tempo latente, onde acontece a análise visual, auditiva e sensorial para determinar a direção e velocidade da bola que acarreta um planejamento neuromotor da defesa. Aproximadamente nesta atividade são perdidos de 80 a $90 \%$ do tempo de defesa. Imediatamente acontece a reação neuromotora que leva 21 a 34 centésimos e a ação de defesa com 30 centésimos. O único meio do atleta do voleibol praticar a defesa é pela reação de antecipação, prevendo local que vai ser efetuado o remate e deslocando antes da bola ser cortada (WILLIAMS; HODGES, 2005). Para essa antecipação defensiva ocorrer o voleibolista depende de um excelente analisador visual (JAFARZADEHPUR; AAZAMI; BOLOURI, 2007), do tempo de reação visual (MONTÉS-MICÓ. et al., 2007) e da percepção (GRÉHAIGNE; GODBOUT; BOUTHIER, 2001). Somente com antecipação um jogador de voleibol consegue fazer a defesa porque a bola é muito veloz e o tempo de latência visual é de 200 milésimos de segundo, que gera o futuro movimento (MARUENDA, 2004), velocidade inferior as ações de ataque do voleibol. Somado ao aspecto visual o esportista precisa possuir apurada memória (declarativa e de procedimento) para efetuar adequada defesa (MARQUES JÚNIOR, 2008b). Este ocorrido somente é para ataques bem realizados porque atividades fáceis de defesa o atleta nem sempre precisa se antecipar para chegar na bola. $\mathrm{O}$ que essas evidências científicas tem haver com o bloqueio? Como o atleta de bloqueio não se preocupa em marcar a bola e faz o fundamento marcando a paralela ou a diagonal, as chances de defesa são mínimas. É sabido que um bom 
bloqueio facilita a defesa. Então, recomenda-se no modelo de jogo a execução do bloqueio tentando interceptar o remate porque as chances de defesa podem ser maiores por causa do amortecimento da bola que bate nas mãos do bloqueador, nos ataques mais fáceis para a defesa, a perfeita marcação deste fundamento que não dá chance para uma cortada forte podem propiciar num remate direcionado para fora porque o bloqueio vai fazer o ponto e o atacante tira muito a bola desse fundamento e erra a quadra. Outros problemas podem acontecer com o cortador que enfrenta um bloqueio adversário que tenta impedir sua tarefa ofensiva e conseqüentemente pode facilitar a defesa. Qual é a melhor região para o jogador se posicionar antes de fazer a defesa? Não existe uma região da quadra, o atleta precisa ficar onde ocorre mais ataques ou permanecer na diagonal porque possui uma área maior que facilita os remates.

Espera-se que esta revisão do modelo de jogo deixe de ser uma teoria e torne brevemente uma prática habitual de jogar o voleibol de dupla na areia.

\section{CONSIDERAÇÕES FINAIS}

O modelo de jogo sugerido neste artigo recomenda alterações no do voleibol atual. Porém, necessita de um acompanhamento constante da teoria e da prática para esta maneira de jogar se tornar aprovado pelos técnicos e cientistas. Espera-se que esta revisão proporcione uma divulgação dessas idéias com o intuito dos técnicos colocarem em prática o mais rápido possível. Contudo, os cientistas precisam acompanhar esse modelo de jogo para determinarem a sua eficácia.

\section{Referências}

ARRUDA, M.; HESPANHOL, J. E. Fisiologia do voleibol. São Paulo: Phorte, 2008. p. 75-82. . Saltos verticais: procedimentos de avaliação em desportos coletivos. São Paulo: Phorte, 2008b. p. 28. BAHR, R.; REESER, J. C. Injuries among world-class professional beach volleyball players. Am J Sports Med. v. 31, n. 1, p. 119-25, 2003.

BENETTI, G.; SCHNEIDER, P.; MEYER, F. Os benefícios do esporte e a importância da treinabilidade da força muscular de pré-púberes atletas de voleibol. Rev Bras Cineantropom Desempenho Hum., v. 7, n. 2, p. 87-93, 2005.

BIZZOCCHI, C. O voleibol de alto nível: da iniciação à competição. 2. ed. São Paulo: Manole, 2004. p. 112114. 
CAVALHEIRO, J. J.; TAVARES, F. A influência da eficácia da manchete sobre a eficácia da recepção do serviço, no jogo de voleibol. In: MESQUITA, I.; MOUTINHO, C.; FARIA, R. (Ed.). Investigação em voleibol. estudos ibéricos. Porto: Universidade do Porto, 2003. p. 262-70.

CÉSAR, B; MESQUITA, I. Caracterização do ataque do jogador oposto em função do complexo do jogo: estudo aplicado no voleibol feminino de elite. Rev Bras Educ Fís Esp., v. 20, n. 1, p. 59-69, 2006.

CEZARANO, M.; ROCHA, C. M. A distribuição dos levantamentos no voleibol infanto-juvenil feminino. Rev Digit. v. 11, n. 101, p. 1-8, 2006. Disponível em: www.efdeportes. Acesso em: 21 set. 2006.

COLLET, C. et al. Processo de ensino-aprendizagem-treinamento no voleibol infantil masculino em Santa Catarina. Rev Educ Fís/UEM., Maringá, . v. 18, n. 2, p. 147-59, 2007.

COSTA, L. C. A.; NASCIMENTO, J. V. O ensino da técnica e da tática: novas abordagens metodológicas. Rev Educ Fis, UEM, Maringá, v. 15, n. 2, p. 49-56, 2004.

CUNHA, P.; MARQUES, A. A eficácia em voleibol. Estudo da relação entre a qualidade do $1^{\circ}$ toque e a eficácia do ataque em voleibolistas portugueses da $1^{\text {a }}$ divisão. In: MESQUITA, I.; MOUTINHO, C.; FARIA, R. (Ed.). Investigação em voleibol: estudos ibéricos. Porto: Universidade do Porto, 2003. p. 180-9.

DEPRÁ, P. P.; BRENZIKOFER, R. Comparação de atletas do voleibol através da análise cinemática e dinâmica de trajetória de bolas de saque. Rev Educ Fís/UEM., Maringá, v. 15, n. 1, p. 7-15, 2004.

FORD, P.; HODGES, N. J.; WILLIAMS, M. Examining action effects in the execution of a skilled soccer kick by using erroneous feedback. Journal of Motor Behavior, v. 39, n. 6, p. 481-490, 2007.

GARGANTA, J. (Re) fundar os conceitos de estratégia e tática nos jogos desportivos coletivos, para promover uma eficácia superior. Rev Bras Educ Fís Esp., v. 20, supl. 5, p. 201-3, 2006.

GASPAR, P.; FERREIRA, J. P.; PÉREZ, L. M. Tomadas de decisão no desporto: o seu ensino em jovens atletas. Rev Mackenz Educ Fís Esp., v. 4, n. 4, p. 95-111, 2005.

GIATSIS, G. The effect of changing the rule on score fluctuation and match duration in the FIVB womens`s beach volleyball. Int J Perfor Analys Sport, v. 3, n. 1, p. 57-64, 2003.

GIATSIS, G.; TZETZIS, G. Comparison of performance for winning and losing beach volleyball teams on different court dimension. Int J Perfor Analys Sport., v. 3, n. 1, p. 65-74, 2003.

GOUVÊA, F. L.; LOPES, M. B. L. Incidência do ataque no voleibol infanto-juvenil feminino. Movim Percep. Pinhal, v. 9, n. 12, p. 168-183, 2008.

GRECO, P. J. Conhecimento técnico-tático: eixo pendular da ação tática (criativa) nos jogos esportivos coletivos. Rev Bras Educ Fís Esp, v. 20, supl. 5, p. 210-2, 2006. 
GRÉHAIGNE, J.-F.; GODBOUT, P.; BOUTHIER, D. The foundations of tactics and strategy in team sports. J Teach Phys Educ. v. 18, n. 2, p. 159-74, 1999.

HESPANHOL, J. E. et al. Desempenho do salto vertical, anaeróbio e velocidade em voleibolista de areia em dois ambientes. Rev Bras Educ Fís Esp. v. 20, n. 5, p. S473, 2006.

JAFARZADEHPUR, E.; AAZAMI, N.; BOLOURI, B. Comparison of saccadic eye movements and facility of ocular accommodation in female volleyball players and non-players. Scand J Med Sports. v. 17, n. 2, p. 186-90, 2007.

JOÃO, P. V. et. al. Análise comparativa entre o jogador líbero e os recebedores prioritários na organização ofensiva, a partir da recepção do serviço em voleibol. Rev Port Ciên Desp. v. 6, n. 3, p. 318-28, 2006.

LACERDA, D.; MESQUITA, I. Caracterização da organização do processo ofensivo, a partir da recepção do serviço, no voleibol de praia de elite. In: MESQUITA, I.; MOUTINHO, C.; FARIA, R. (Ed.). Investigação em voleibol. Estudos ibéricos. Porto: Universidade do Porto, 2003. p. 150-9.

MARQUES JÚNIOR, N. K. Uma preparação desportiva para o voleibol. Rev Min Educ Fís. v. 10, n. 2, p. 49$73,2002$.

. Periodização tática: uma nova organização do treinamento para duplas masculinas do voleibol na areia de alto rendimento. Rev Min Educ Fís. v. 14, n. 1, p. 19-45, 2006.

. Altas temperaturas. Movim Percep., v. 9, n. 12, p. 6-17, 2008.

. O efeito do treino da visão periférica no ataque de iniciados do futsal: um estudo na competição. 2008. 157f. Dissertação (Mestrado) - Universidade Castelo Branco, Rio de Janeiro, 2008.

.; SILVA, K. Identificando os motivos das lesões no atleta profissional do voleibol na quadra. Rev Min Educ Fís., v. 14, n. 2, p. 68-77, 2006.

MARUENDA, F. B. Can the human eye detect na offside position during a football match? Brit Med $J$. v. 329, p. 18-25, 2004.

MENEZES, F. S.; MENEZES, R. B. P. X.; SANTOS, G. M. Análise das lesões mais freqüentes nos atletas de voleibol de praia masculino de elite. Rev Digit., v. 12, n. 116, p. 1-7, 2008. Disponível em: www.efdeporetes.com. Acesso: 13 jan. 2008.

MESQUITA, I.; GRAÇA, A. O conhecimento estratégico de um distribuidor de alto nível. Trein. Desp., 2002.

.; TEIXEIRA, J. Caracterização do processo ofensivo no voleibol de praia masculino de elite mundial, de acordo com o tipo de ataque, a eficácia e o momento do jogo. Rev Bras Ciênc Esporte, v. 26, n. 1, p. 3349, 2004. 
MONTÉS-MICÓ, R. et al. Eye-hand and eye-foot visual reaction times of young soccer players. Optometry. v. 7, n. 12, p. 775-780, 2007.

MORALES, J. C. P.; GRECO, P. J. A influência de diferentes metodologias de ensino-aprendizagemtreinamento no basquetebol sobre o nível de conhecimento tático processual. Rev Bras Educ Fís Esp. v. 21, n. 4, p. 291-299, 2007.

NOCE, F.; SAMULSKI, D. T. Análise do estresse psíquico em atacantes no voleibol de alto nível. Rev Paul Educ Fís. v. 16, n. 2, p. 113-129, 2002.

OLIVEIRA, R.; MESQUITA, I.; OLIVEIRA, M. Caracterização da eficácia do bloqueio no voleibol de elevado rendimento competitivo. Rev Digit., v. 10, n. 84, p. 1-11, 2005. Disponível: www.deportes.com. Acesso em: 24 abr. 2005.

PALAO, J. M.; SANTOS, J. A.; UREÑA, A. Efecto del tipo y eficacia del saque sobre el bloqueo y rendimiento del equipo en defensa. Rend Dep., n. 8, p. 1-19, 2004. Disponível em: www.rendimientdeportivo.com. Acesso em: 13 set. 2006.

RAMOS, M. H. K. P.; et al., Estrutura interna das ações de levantamento das equipes finalistas da superliga masculina de voleibol. Rev Bras Ciên Mov., v. 12, n. 1, p. 33-7, 2004.

RESENDE, R.; SOARES, J. Caracterização da atividade física em voleibol de praia. In: MESQUITA, I.; MOUTINHO, C.; FARIA, R. (Ed.). Investigação em voleibol: estudos ibéricos. Porto: Universidade do Porto, 2003. p. 253-261.

RIZOLA NETO, A. Uma proposta de preparação para equipes jovens de voleibol feminino. 2003. Dissertação (Mestrado em Educação Física) - Faculdade de Educação Física, Universidade Estadual de Campinas, Campinas, 2003.

ROCHA, C. M.; BARBANTI, V. J. Uma análise dos fatores que influenciam o ataque no voleibol masculino de alto nível. Rev Bras Educ Fís Esp., v. 18, n. 4, p. 303-314, 2004.

RUSSO, P. A visão do técnico. In: CONGRESSO INTERNACIONAL GSSI DE CIÊNCIAS DO ESPORTE, 2. 2002, São Paulo. Anais... São Paulo, 2002.

SOUZA, A. P. S.; OLIVEIRA, C. A.; OLIVEIRA, M. A. Medida de tempo de reação simples em jogadores profissionais de voleibol. Rev Digit., v. 10, n. 93, p. 1-9, 2006. Disponível em: www.efdeportes.com. Acesso em: 15 fev. 2006.

STEFANELLO, J. Situação de estresse no vôlei de praia de alto rendimento: um estudo de caso com uma dupla olímpica. Rev Port Ciên Desp., v. 7, n. 2, p. 232-44, 2007.

UGRINOWITSCH, C.; UEHARA, P. Modalidades esportivas coletivas: o voleibol. In: DE ROSE JÚNIOR, D. (Org.). Modalidades esportivas coletivas. Rio de Janeiro: Guanabara Koogan, 2006. p. 167-168, 171-172. 
UREÑA, A. et al. La facilitación defensiva através del saque en el voleibol femenino de alto nivel. Rev Motric. v. 6, p. 176-178, 2000.

VIEIRA, L. F. et al. Estado de humor e desempenho motor: um estudo com atletas de voleibol de alto rendimento. Rev Bras Cineantropom Desempenho Hum., v. 10, n. 1, p. 62-68, 2008.

WILLIAMS, M.; HODGES, N. J. Practice, instruction and skill acquisition in soccer: challenging tradition. $J$ Sports Sci., v. 23, n. 6, p. 637-50, 2005. 
Nelson Kautzner Marques Júnior

Universidade Castelo Branco

Mestrando em Ciência da Motricidade Humana

E-mail: nk-junior@uol.com.br

Rua 5 - Lote 12 - Quadra D - Loteamento Jardim Fluminense

Itaipu - Niterói - Rio de Janeiro - Brasil

CEP: 24344-080

Tel.: Oxx (21) 2609-7904

\section{Referência do artigo:}

\section{ABNT}

MARQUES JÚNIOR, N. K. Um modelo de jogo para o voleibol na areia. Conexões, v. 6, n. 3, p. 13-26, 2008.

\section{APA}

MARQUES JÚNIOR, N K, (2008). Um modelo de jogo para o voleibol na areia. Conexões, 6(3), 13-26.

\section{VANCOUVER}

MARQUES JÚNIOR NK. Um modelo de jogo para o voleibol na areia. Conexões, 2008, 6(3): 1-26.

Recebido: 02/01/2008

Aceito para publicação em: out. 2008 